\title{
The Relationship between Income Tax Burden and $R \&$ D Investment of High-Tech Enterprises
}

\author{
Mengyao Zheng \\ School of Economics, Jinan University, Guangzhou, China \\ Email: zhengmengyao106@163.com
}

How to cite this paper: Zheng, M.Y. (2019) The Relationship between Income Tax Burden and R \& D Investment of High-Tech Enterprises. Modern Economy, 10, 720-729.

https://doi.org/10.4236/me.2019.103049

Received: February 26, 2019

Accepted: March 17, 2019

Published: March 20, 2019

Copyright $\odot 2019$ by author(s) and Scientific Research Publishing Inc. This work is licensed under the Creative Commons Attribution International License (CC BY 4.0).

http://creativecommons.org/licenses/by/4.0/

(c) (i) Open Access

\begin{abstract}
This paper takes 162 Chinese high-tech listed companies as samples to study the relationship between corporate income tax burden and R \& D investment in short-term and medium-term. Then selects electronic information industry and aerospace industry to make corresponding descriptive statistics and regression analysis to test whether the corporate income tax burden is affected by the industry's $\mathrm{R} \& \mathrm{D}$ investment, and further verify whether the relationship between corporate income tax burden and $\mathrm{R} \& \mathrm{D}$ investment is consistent with the industry-wide analysis results. It compares tax burden dependence in different industries. The empirical finding: whether in the short-term or medium-term, reducing the corporate income tax burden can promote the company's R \& D investment, and in the medium term performance is more significant. The regression analysis of the electronic information industry and the aerospace industry also verified this result and found that reducing the tax burden on the aerospace industry's $\mathrm{R} \& \mathrm{D}$ investment is stronger than the electronic information industry.
\end{abstract}

\section{Keywords}

R \& D Investment, Industry Dependence

\section{Introduction}

In the context of economic globalization, the exchanges between countries have become increasingly close, and competition has become more and more fierce. The improvement of innovation ability has directly affected the improvement of a country's economic level. In recent years, the Chinese government has paid more and more attention to science and technology. And also continue to increase financial allocations to it according to the relevant statistics of China Science and Technology Statistical Yearbook from 2007 to 2017 [1] below. In the 
past ten years, the total amount of $\mathrm{R} \& \mathrm{D}$ investment in China has increased from 371.02 billion Yuan in 2007 to 176.61 billion Yuan in 2017. At the same time, the proportion of R \& D investment in GDP has also increased from $1.49 \%$ in 2007 to $2.13 \%$ in 2017 . It can be seen that China has begun to attach importance to the improvement of scientific and technological innovation capabilities and realized the importance of technological innovation for economic development.

In 2017, the country invested a total of 176.61 billion Yuan in research and experimental development ( $\mathrm{R} \& \mathrm{D})$. According to industry classification, among the industrial enterprises above designated size, there are 8 major industries had been invested in research for more than 50 billion Yuan as shown in Figure 1 below. The proportion of these eight industries accounted for $65.2 \%$ of the total, and there are only two industries with $\mathrm{R} \& \mathrm{D}$ intensity over $2 \%$. Computer, communications and other electronic equipment manufacturing have invested the most in $\mathrm{R} \& \mathrm{D}$, exceeding 100 billion, but the intensity is less than $2 \%$. The $\mathrm{R}$ $\& \mathrm{D}$ intensity of railway, shipbuilding, aerospace and other transportation equipment manufacturing industries is up to $2.53 \%$, but $\mathrm{R} \& \mathrm{D}$ investment is less than 50 billion. On the whole, there are significant differences in R \& D investment in various industries, and the gap in $\mathrm{R} \& \mathrm{D}$ intensity is more obvious.

In order to explore the relationship between high-tech enterprise income tax and its R \& D investment, this paper selects panel data of 162 high-tech listed Chinese companies for 2008-2017 for a total of ten years. Using Schumpeter's innovation theory, Solo model theory, etc., through correlation test, Hausman test, fixed-effect model regression to verify whether the tax burden of high-tech enterprises and R \& D investment are related.

\section{Literature Review}

There are many concerns about R \& D investment. Theoretical and empirical

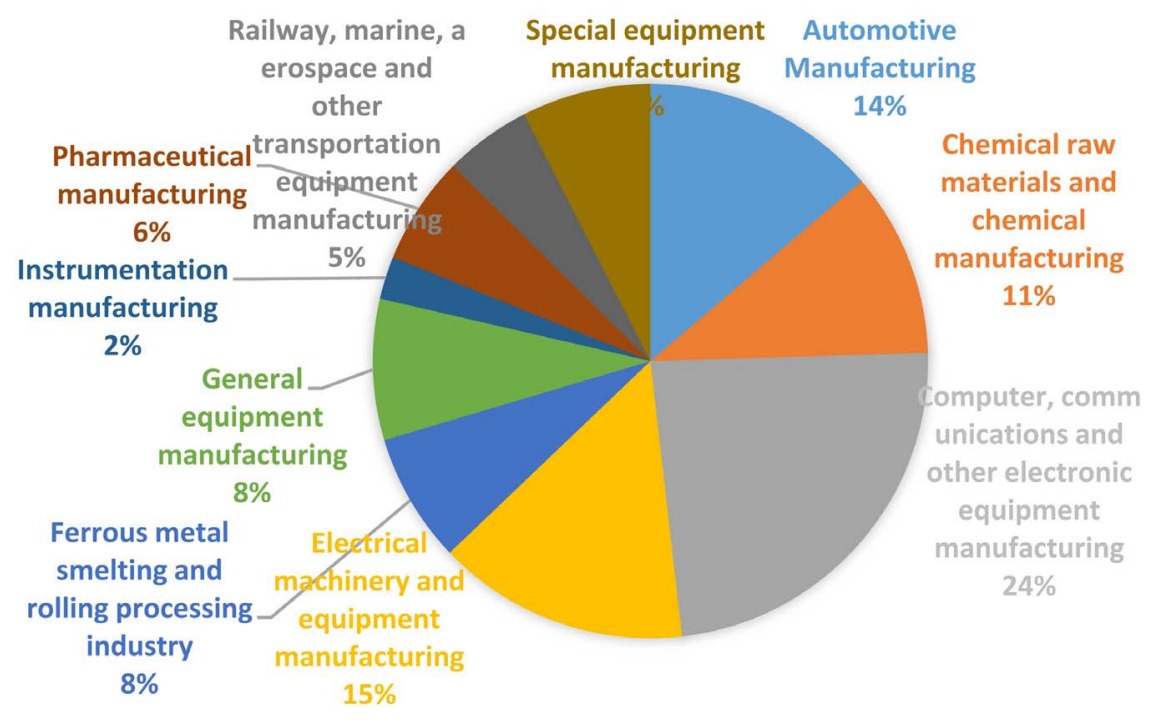

Figure 1. Industry R \& D investment pie chart. 
research has gradually shifted from macro external factors to internal characteristics. There are many kinds of literature on $\mathrm{R} \& \mathrm{D}$ innovation and the scope of research is also wide. From the observation and demonstration of $\mathrm{R} \& \mathrm{D}$ behavior and its influencing factors to the relationship between $\mathrm{R} \& \mathrm{D}$ investment and corporate value, there are many related types of research, and they have always been hot spots. For example, considering external factors such as macroeconomic environment, policy support, government subsidies, tax incentives, etc.; internal factors such as firm size, profitability, human resources, asset-liability ratio, capital structure, etc., are related to R \& D investment. Bernstein (1986) used 27 companies' time series data from 1975 to 1980 to evaluate Canadian R \& $\mathrm{D}$ tax incentives (including $\mathrm{R} \& \mathrm{D}$ investment tax credits and special research subsidies) for $\mathrm{R} \& \mathrm{D}$ investment. As a result, it was found that the tax incentives increased by US $\$ 1$ each, and the new amount of R \& D investment would exceed US\$1 [2]. Iryna Radionova and Olena Boger (2014) studied the relationship between tax burden and innovation activities in both theory and practice. Firstly, the relationship between tax burden and innovation activity is analyzed theoretically. Then, through panel data analysis of eight indicators of $27 \mathrm{EU}$ countries, the results show that the possible result is that the increase of tax burden will limit the number of innovation activities [3]. Yohei Kobayashi (2014) conducted research on Japanese SMEs. The empirical results show that tax incentives can indeed promote $\mathrm{R} \& \mathrm{D}$ investment, but this effect will vary depending on the industry and scale of the company, this effect is stronger for companies with weaker liquidity than for companies with strong liquidity [4]. From the foreign research on the impact of tax policies and other preferential policies on $\mathrm{R} \& \mathrm{D}$ expenditure, it is found that the economic cycle of enterprises is different, the industry is different, and the impact of tax policies and other preferential policies on R \& D expenditure will be different. Domestic scholars have studied the $\mathrm{R} \& \mathrm{D}$ investment of enterprises from different angles. The impact of the tax burden on an R \& D investment of enterprises is still controversial. Different scholars use different empirical data, and the conclusions are even contradictory. Ma W. H (2011) used the random effects panel model to analyze the relevant data of 67 SME board listed high-tech manufacturing enterprises during the period of 2007-2009 and found that the tax policy has a significant role in promoting R \& D [5]. Luo Fujii and Wang Jing (2016) used the data of A-share listed companies in Shanghai and Shenzhen stock markets from 2009 to 2012 as a sample. Using the hierarchical regression model, it was found that corporate income tax had a significant negative impact on $\mathrm{R} \& \mathrm{D}$ expenditure, but due to the existence of debt tax shield the capital structure can alleviate the constraints of the corporate tax burden on R \& D expenditure [6]. As far as the research results are concerned, many scholars who choose to use enterprise data for analysis at the micro level only use a time series of three to five years. If the time is too short, it may not be able to study the true correlation and make the conclusion unconvincing. For the research of sub-industries, the research at home and abroad is not too much. The domestic research started late, and the academic 
circles have not reached a unified conclusion.

\section{Empirical Analysis}

\subsection{Sample Selection}

Considering that high-tech enterprises are the most concentrated areas for R \& $\mathrm{D}$ investment of Chinese enterprises, and the research object is more reliable for high-tech enterprises. This paper selects Shanghai and Shenzhen A-share manufacturing listed high-tech companies as the sample data from 2008 to 2017.The related data are all from Wind database ${ }^{1}$. To ensure the robustness of the results, this paper introduced the related processing: 1) Remove within 3 years of newly listed companies, such companies do not have the continuity of data; 2) Remove the "st" companies, the companies are at risk of delisting and abnormal operating conditions; 3) Remove the missing data and financial indicators of extreme abnormal data.The sample size was selected as 162 .

\subsection{Variable Selection}

The panel data model, in simple terms, is a mixture of time series and section data. Compared with cross-section data and time series data, the panel data model can construct a more realistic behavior equation, which can analyze the data more comprehensively. Use the basic settings of the panel data model:

$$
Y_{i t}=\alpha_{i t}+\beta_{i t} X_{i t}+\mu_{i t}
$$

Among them, $Y_{i t}$ is the interpreted variable, $X_{i t}$ is the vector of explanatory variables, $\alpha_{i t}$ is the constant term of the model, $\beta_{i t}$ is the coefficient vector corresponding to the explanatory variable vector, and $\mu_{i t}$ is the random interference term.

Summarizing the previous studies, it is found that the decline of the corporate tax burden in the short term can promote the increase of $\mathrm{R} \& \mathrm{D}$ investment. Relevant variables are defined as shown in Table 1 . Therefore, the empirical model of this paper is as follows:

$$
\begin{aligned}
R D_{i t}= & A+\alpha E T R_{i t}+\beta_{1} \text { LASTETR }_{i t}+\beta_{2} \operatorname{LASTRD}_{i t}+\beta_{3} \operatorname{SIZE}_{i t} \\
& +\beta_{4} L E V_{i t}+\beta_{5} \operatorname{SALE}_{i t}+\beta_{6} R O E_{i t}+\mu_{i t}
\end{aligned}
$$

In order to make the indicators comparable, this paper uses the logarithmic index as the research variable and uses the logarithm of the R \& D investment amount as the $\mathrm{R} \& \mathrm{D}$ input index.

\subsection{Descriptive Statistics and Multi-Colinearity Test}

1) Descriptive Statistics

${ }^{1}$ Wind info is China's leading financial data, software and information service enterprise, the headquarters is located in Shanghai Lujiazui financial center. In the domestic market, Wind information of customers including more than $90 \%$ of Chinese securities companies, fund management companies, insurance companies, Banks and investment companies, financial companies; In the international market, has been approved by the China securities regulatory commission $75 \%$ of qualified foreign institutional investors (QFII) agency is Wind information of customers. 
Table 1. Relevant variables defined.

\begin{tabular}{|c|c|c|c|}
\hline & $\begin{array}{l}\text { Variable } \\
\text { symbol }\end{array}$ & Variable name & Variable definitions \\
\hline $\begin{array}{l}\text { Dependent } \\
\text { variable }\end{array}$ & $\mathrm{RD}$ & $\mathrm{R} \& \mathrm{D}$ investment & $\begin{array}{l}\text { The natural logarithm of the } \\
\mathrm{R} \& \mathrm{D} \text { investment in this period }\end{array}$ \\
\hline \multirow[t]{3}{*}{$\begin{array}{l}\text { Independent } \\
\text { variables }\end{array}$} & ETR & Corporate tax burden & $\begin{array}{l}\text { (income tax expense - deferred } \\
\text { income tax expense)/total profit }\end{array}$ \\
\hline & LASTRD & Last $\mathrm{R} \& \mathrm{D}$ investment & RD lag phase I \\
\hline & LASTETR & Last corporate tax burden & ETR lag phase I \\
\hline \multirow{4}{*}{$\begin{array}{c}\text { Control } \\
\text { variables }\end{array}$} & ROE & Profitability & The total profit/total assets \\
\hline & SIZE & Company size & The natural logarithm of total assets \\
\hline & LEV & Asset-liability ratio & Total debt/total assets \\
\hline & SALE & Total profit & Natural logarithm of total profit \\
\hline
\end{tabular}

To directly show the range of related variables and volatility in the whole sample, the descriptive statistics of the whole samples is presented in Table 2.

The maximum value of $\mathrm{R} \& \mathrm{D}$ investment is 12.67427 , the minimum is 3.076042 , and the average value is 8.526395 , indicating that the $\mathrm{R} \& \mathrm{D}$ investment of different enterprises is quite different. The maximum and minimum corporate income tax burdens are 0.912797 and 0.002154 , respectively, indicating that the income tax burdens of different enterprises in different years vary greatly. The average corporate income tax burden is 0.140936 , and the standard deviation is 0.071444 , which indicates that the average actual tax burden of high-tech enterprises is similar to the nominal tax rate of $15 \%$. The small standard deviation also indicates that the gap between each sample and the mean is small, consistent with common sense.

2) Multi-Colinearity test

If there is a collinearity problem between the explanatory variable and the control variable, the regression system will be made larger when the regression analysis is performed, and some variables that have an influence on the response result are excluded from the external problem, so the collinear diagnosis of the variable is required. In order to identify the multicollinearity problem of the model, we have passed the VIF test. The variance expansion factor from Table 3 is less than 10, and the average variance expansion factor is 2.19 less than 3 . It can be seen that there is no serious multi-collinearity problem.

\subsection{Empirical Analysis and Results}

1) Industry-wide regression analysis

a) Hausman test

It can be seen from the test results of Table 4 . Prob $>\operatorname{chi}^{2}=0.0184$, the original hypothesis cannot be rejected. This paper should use the random effects model panel analysis method. 
Table 2. Major variable description.

\begin{tabular}{cccccc}
\hline Variable & Obs & Mean & Std. & Min & Max \\
\hline RD & 1620 & 8.526395 & 1.356476 & 3.076042 & 12.67427 \\
ETR & 1620 & 0.140936 & 0.071444 & 0.002154 & 0.912797 \\
LASTRD & 1458 & 8.403103 & 1.324424 & 3.076042 & 12.40222 \\
LASTETR & 1458 & 0.1394287 & 0.066467 & 0.002154 & 0.776462 \\
SIZE & 1620 & 12.06164 & 1.269966 & 8.13684 & 15.66546 \\
LEV & 1620 & 0.336137 & 0.17613 & 0.011034 & 0.828761 \\
ROE & 1620 & 0.135077 & 0.110697 & 0.000935 & 0.799075 \\
SALE & 1620 & 18.5763 & 1.145841 & 15.2336 & 23.07339 \\
\hline
\end{tabular}

Table 3. VIF test result.

\begin{tabular}{ccc}
\hline Variable & VIF & $1 /$ VIF \\
\hline Size & 8.64 & 0.115738 \\
Sale & 6.07 & 0.164629 \\
Lastrd & 2.44 & 0.410092 \\
Lev & 2.29 & 0.436401 \\
Roe & 1.77 & 0.564479 \\
Etr & 1.42 & 0.704248 \\
Lastetr & 1.32 & 0.759166 \\
Mean VIF & 2.19 & \\
\hline
\end{tabular}

Table 4. Test result.

\begin{tabular}{ccccc}
\hline & $(\mathrm{b}) \mathrm{fe}$ & $(\mathrm{B}) \mathrm{re}$ & $(\mathrm{b}-\mathrm{B})$ Difference & $\mathrm{sqrt}\left(\mathrm{diag}\left(\mathrm{V} \_\mathrm{b}-\mathrm{V} \_\mathrm{B}\right)\right)$ S.E. \\
\hline Etr & 0.292628 & -0.4608526 & 0.7534806 & 0.1205433 \\
Lastetr & 0.5082543 & -0.0965579 & 0.6048122 & 0.1263487 \\
Lastrd & 0.4317796 & 0.6968605 & -0.2650809 & 0.0162263 \\
Lev & -0.218415 & -0.1145508 & -0.1038642 & 0.1302887 \\
Size & 0.5733649 & 0.2562571 & 0.3171077 & 0.0325122 \\
Roe & 1.262777 & 0.8758668 & 0.3869099 & 0.1701814 \\
Sale & 0.0622902 & 0.0658744 & -0.003584 & 0.0249909 \\
_cons & -3.341126 & -1.557285 & -1.783841 & 0.3030067 \\
\hline
\end{tabular}

$\mathrm{b}=$ consistent under Ho and Ha; obtained from xtreg; $\mathrm{B}=$ inconsistent under Ha, efficient under Ho; obtained from xtreg; Test: Ho: difference in coefficients not systematic; chi2 $(7)=(\mathrm{b}-\mathrm{B})^{\prime}\left[\left(\mathrm{V} \_\mathrm{b}-\right.\right.$ V_B $\left.)^{\wedge}(-1)\right](\mathrm{b}-\mathrm{B})=2.99$. Prob $>\mathrm{chi}^{2}=0.0184$.

b) Random effect model regression results and analysis

From the results of Table $5, \mathrm{R}^{2}$ is 0.9640 , indicating that the whole model is better and the interpretation is strong enough. The coefficient of Etr is -0.4608526 , which means that for every unit of corporate income tax reduction, 
Table 5. Random effect model regression results.

\begin{tabular}{ccccccc}
\hline Rd & Coef. & Std. Err. & $\mathrm{t}$ & $\mathrm{P}>|\mathrm{t}|$ & $95 \%$ Conf. & Interval \\
\hline Etr & -0.4608526 & 0.219876 & -2.10 & 0.036 & -0.8918016 & -0.0299036 \\
Lastetr & -0.0965579 & 0.2283712 & -0.42 & 0.672 & -0.5441572 & 0.3510414 \\
Lastrd & 0.6968605 & 0.0160491 & 43.42 & 0.000 & 0.6654048 & 0.7283162 \\
Lev & -0.1145508 & 0.1010893 & -1.13 & 0.257 & -0.3126822 & 0.0835806 \\
Size & 0.2562571 & 0.0413503 & 6.20 & 0.000 & 0.175212 & 0.3373023 \\
Roe & 0.8758668 & 0.2685758 & 3.26 & 0.001 & 0.3494679 & 1.402266 \\
Sale & 0.0658744 & 0.035326 & 1.86 & 0.062 & -0.0033633 & 0.1351121 \\
_cons & -1.557285 & 0.2734939 & -5.69 & 0.000 & -2.093323 & -1.021247 \\
\hline
\end{tabular}

$\mathrm{R}$-sq $=0.9640$. F test that all $\mathrm{u} \_\mathrm{i}=0: \mathrm{F}(197,1379)=2.76$ Prob $>\mathrm{F}=0.0000$.

the company's Rd will increase by $46.09 \%$. Looking at the control variables, the Lastetr coefficient is -0.0965579 , which is also negatively correlated with the R \& $\mathrm{D}$ investment of the enterprise, and the intensity of the action is weaker than this period. On the whole, the last phase of $\mathrm{R} \& \mathrm{D}$ investment is the most important factor affecting $\mathrm{R} \& \mathrm{D}$ investment in this period. The coefficient of Lastrd is significantly positive under the $1 \%$ level significant, and its coefficient is 0.6968605 , which indicates that $\mathrm{R} \& \mathrm{D}$ has thick and thin characteristics. It requires an accumulating process. The intensity of $\mathrm{R} \& \mathrm{D}$ in the previous period will affect the $\mathrm{R} \& \mathrm{D}$ intensity of this period and will have a positive promotion effect. The coefficient of Size is at the $1 \%$ level significant, which supports the view of the Schumpeter Innovation Model that large companies have a greater advantage in economies of scale, risk-taking, monopoly profits and talent pools because It also has stronger R \& D and innovation capabilities and motivation. Looking at other variables, both sales and roe are significantly positive. The profitability of enterprises is an important factor affecting corporate $\mathrm{R} \& \mathrm{D}$ decisions. Companies with good earnings have a stronger willingness to invest more in $\mathrm{R} \& \mathrm{D}$ innovation.

The positive incentives for tax incentives have proven to be universal in the industry, but according to the above analysis, the $\mathrm{R} \& \mathrm{D}$ investment among various industries may be significantly different. Whether there is a difference in the dependence of different industries on tax burden, further research is needed.

2) Industry regression analysis

The "High-tech Fields Supported by the State" announced by the Ministry of Science and Technology divides high-tech enterprises into electronic information, biology and new medicine, aerospace, new materials, high-tech services, new energy and energy conservation, resources and environment, advanced manufacturing and Automated eight major industries ${ }^{2}$. According to the "Statistical Bulletin of National Science and Technology Funds Investing in 2017" [1]

2"High-tech Fields Supported by the State" was announced by the Ministry of Science and Technology of China.

(http://www.innocom.gov.cn/gxjsqyrdw/ztwj/201602/5e7d1f23faf547de9de2aff3ce9f434a.shtml) 
issued by the National Bureau of Statistics in 2018, The electronic information industry with the most investment in R \& D (200.28 billion yuan) and the aerospace industry with the highest R \& D expenditure $(2.53 \%)$ were selected as the industry representative to do the further regression analysis.

a) Regression analysis in the electronic information industry

It can be seen from Table 6 that $\mathrm{R}^{2}$ is equal to 0.9815 , and the overall performance of the model is good. The income tax burden of enterprises is significantly negatively correlated with $\mathrm{R} \& \mathrm{D}$ investment. Consistent with the regression results of the whole sample, the lower the corporate income tax burden, the higher the R \& D investment. The impact of R \& D investment and ROE on the $\mathrm{R} \& \mathrm{D}$ investment of enterprises in the previous period is more significant. From the correlation coefficient, the correlation coefficient of ROE is the largest, up to $81.95 \%$. This is also consistent with the above analysis. The profitability of the company itself is still an important factor affecting the company's research and development decisions. The negative coefficient of the previous enterprise income tax is positively opposite to the above analysis, but the coefficient is not significant enough to be convincing. The reason for this is related to the characteristics of the industry itself. The electronics industry is a technology-intensive industry, and its technological content determines its competitiveness. The electronics industry has rapid technological progress, short life cycle, wide application range, and high product added value. , economic benefits and other characteristics.

b) Regression analysis in the aerospace industry

From the regression results in Table 7 below, the company's current R \& D investment is negatively correlated with the current corporate tax burden and the previous corporate tax burden, while the previous $\mathrm{R} \& \mathrm{D}$ investment is positively correlated with the current period. The conclusion is the same as the above analysis. The same as the electronic information industry, the current R \& D investment in the aerospace industry is closely related to the previous $R \& D$ investment, which should be the generality of all high $\mathrm{R} \& \mathrm{D}$ investment industries. The R \& D investment of the enterprise is negatively correlated with the

Table 6. Regression results in the field of electronic information.

\begin{tabular}{ccccccc}
\hline Rd & Coef. & Std. Err. & $\mathrm{t}$ & $\mathrm{P}>|\mathrm{t}|$ & $95 \%$ Conf. & Interval \\
\hline Etr & -0.713501 & 0.231621 & -3.08 & 0.002 & -1.16747 & -0.25953 \\
Lastetr & 0.0998994 & 0.232086 & 0.43 & 0.667 & -0.35498 & 0.554779 \\
Lastrd & 0.7210401 & 0.018788 & 38.38 & 0.000 & 0.6842163 & 0.7578639 \\
Lev & -0.0029565 & 0.1101886 & -0.03 & 0.979 & -0.2189221 & 0.2130092 \\
Size & 0.2789045 & 0.0480666 & 5.8 & 0.000 & 0.1846957 & 0.3731133 \\
Roe & 0.819513 & 0.2780531 & 2.95 & 0.003 & 0.274539 & 1.364487 \\
Sale & -1.251812 & 0.2806708 & -4.46 & 0.000 & -1.801916 & -0.701707 \\
cons & -0.0029565 & 0.1101886 & -0.03 & 0.979 & -0.2189221 & 0.2130092 \\
\hline
\end{tabular}

$\mathrm{R}-\mathrm{sq}=0.9815$. 
Table 7. Return results in the aerospace industry.

\begin{tabular}{ccccccc}
\hline Rd & Coef. & Std. Err. & $\mathrm{t}$ & $\mathrm{P}>|\mathrm{t}|$ & {$[95 \%$ Conf. } & Interval] \\
\hline Etr & -0.620293 & 0.417499 & -1.49 & 0.137 & -1.43858 & 0.197991 \\
Lastetr & -1.069527 & 0.565592 & -1.89 & 0.059 & -2.17807 & 0.039013 \\
Lastrd & 0.6461097 & 0.04132 & 15.64 & 0.000 & 0.565124 & 0.727095 \\
Lev & -0.268709 & 0.239375 & -1.12 & 0.262 & -0.73787 & 0.200457 \\
Size & 0.3312077 & 0.096899 & 3.42 & 0.001 & 0.141289 & 0.521127 \\
Roe & 0.9045907 & 0.753754 & 1.20 & 0.230 & -0.57274 & 2.381921 \\
Sale & 0.0695911 & 0.080031 & 0.87 & 0.385 & -0.08727 & 0.226448 \\
_cons & -1.96664 & 0.653908 & -3.01 & 0.003 & -3.24828 & -0.685000 \\
\hline
\end{tabular}

$\mathrm{R}-\mathrm{sq}=0.7773$.

current and previous enterprises. That is, the greater the corporate tax burden, the lower the R \& D investment, but the correlation coefficient of the current corporate tax burden is lower than the previous corporate tax burden and the significance is weak. It may be caused by a small number of regression samples. The indicators of corporate size, operating income and return on net assets that reflect corporate profitability are positively correlated with R \& D investment, while the asset-liability ratio coefficient is negative, consistent with previous analysis results. The R2 of the model is 0.7773 , although the regression coefficient is lower than that of the electronic information industry, the overall significance is acceptable.

Through the analysis of the above industries, it can be seen that the income tax burden of enterprises has a negative correlation with the R \& D investment of enterprises, that is, the increase of corporate tax burden will reduce the enthusiasm of enterprises to increase $\mathrm{R} \& \mathrm{D}$ investment. The influence of the electronic information industry is more significant and significant. This is also determined by the characteristics of the electronic information industry. The electronic information industry is developing rapidly, the life cycle is short, and the electronic product replacement technology is faster. The enterprise will invest its own funds in research and development. The risk of the project is very large. When the perceived tax burden increases, the enterprises engaged in this industry will reduce the $\mathrm{R} \& \mathrm{D}$ projects initiated by the investment, and thus avoid the risks of their own funds. The aerospace industry has a long research and development cycle, and the related companies have relatively large funds, which are less sensitive to corporate tax burden than the electronic information industry.

\section{Conclusions}

Based on the combing research of the existing literature and the related innovation theories such as Schumpeter's growth, this paper believes that the R \& D investment of high-tech enterprises is negatively correlated with the income tax burden. And this quantitative analysis and verification found that regardless of 
the whole industry or sub-industry, whether in the current period or the last period, the reduction of corporate income tax can promote high-tech enterprises to increase their research and development investment. In previous studies, the impact of the corporate tax burden on corporate R \& D investment scholars has three different views, positive, negative, and irrelevant. The results of this paper support the second view. Further regression analysis of the electronic information industry and the aerospace industry also confirmed this result. It is also found that the R \& D investment of the aerospace industry is more dependent on the company's burden reduction. Both the current and previous corporate income tax liabilities are negatively correlated with $\mathrm{R} \& \mathrm{D}$ investment, but the $\mathrm{R}$ $\& \mathrm{D}$ investment in the electronic information industry is significantly negatively correlated with the current corporate tax burden. The tax burden is positively correlated. The research and development cycle of the electronic information industry is much shorter than that of the aerospace industry. Therefore, compared with the latter, the electronic information industry has a shorter period of dependence on tax reduction, and more depends on the previous R \& D investment and the overall profitability of the enterprise.

The selection of this paper is 162 high-tech enterprises that are continuously disclosed in 2008-2017. It may not be applicable to the conclusion that the data collection scope is beyond the scope of data collection. At the same time, the conclusion of this paper is mainly for high-tech listed companies, and the research scope cannot include non-listed high-tech enterprises.

\section{Conflicts of Interest}

The author declares no conflicts of interest regarding the publication of this paper.

\section{References}

[1] 2007-2017 "National Science and Technology Funds Investment Statistics Bulletin". http://www.stats.gov.cn/tjsj/zxfb/201710/t20171009_1540386.html

[2] Bemstein, J. (1968) The Effect of Direct and Indirect Tax Incentives on Canadian Industrial R\&D Expenditures. Canadian Public Policy, 3.

[3] Iryna, R. and Olena, B. (2014) Tax Burden and Innovation Activities: The Interrelation Problem. EconomicAnnals-XXL, 5.

[4] Kobayashi, Y. (2014) Effect of R\&D Tax Credits for SMEs in Japan: A Microeconometric Analysis Focused on Liquidity Constraiiits. Small Business Economics, 311-327.

[5] Ma, W.H. (2011) Empirical Research on the Impact of Tax Incentives on Technological Innovation of High-tech Enterprises-Based on Panel Data of Listed HighTech Enterprises. Nanjing University of Finance and Economics, Nanjing.

[6] Luo, K.F and Wang, J. (2016) Corporate Income Tax, Capital Structure and R \& D Expenditure. Scientific Research Management, 44-52. 